\title{
Tres poemes eròtics en català i occità copiats en un cançoner rossellonès
}

\author{
Three erotic poems in catalan and occitan copied in a songbook of Roussillon
}

\author{
ENRIC PRAT / PeP Vila \\ epr00005@gmail.com \\ pepvilamedinya@hotmail.com
}

Institut d'Estudis Gironins

Resum: Editem tres poemes anònims del segle xix, de tema eròtic, dos en català i un en occità, copiats a la fi d'un manuscrit custodiat al Fons Albert Salsas de l'Arxiu Departamental dels Pirineus Orientals de Perpinyà (ADPO), que conté el recull de poemes rossellonesos Obres de fra Pere, de Pere Puiggarí.

Paraules clau: poesia eròtica; Pere Puiggarí; Rosselló; català; occità; francès; ADPO; segle XIX

Abstract: We present the edition of three anonymous erotic poems from the XIXth century, two in Catalan and one in Occitan, from a manuscript preserved in the Fonds Albert Salsas (Archives Départementales des Pyrénées-Orientales, Perpignan - ADPO) that contains the collection Obres de fra Pere by Pere Puiggarí.

Keywords: erotic poetry; Pere Puiggarí; Roussillon; Catalan; Occitan; French; ADPO; XIXth century. 
L'any 2000, dins el volum Poesia eroticoburlesca rossellonesa del s. XIX (Prat / Vila 2000), vam editar un poemari anomenat Obres de fra Pere, de l'erudit, gramàtic i escriptor rossellonès Pere Puiggarí (Perpinyà 1776-1854), juntament amb un altre manuscrit titulat Poésies écrites par M. Jaubert de Passa, que contenia uns poemes anònims probablement només aplegats per Francesc Jaubert de Paçà, d'ambient carnavalesc, provinents de la zona de Prats de Molló. ${ }^{1}$ En el primer cas es tractava d'una col lecció de vint poemes rossellonesos d'entre 1802 i 1819. El títol del recull era de Josep Tastú, que a la seva mort en tenia enllestida una edició que no es va arribar a imprimir.

Aquella col lecció de poesia burlesca, de tema eròtic i amb tendència a la sàtira anticlerical, era aparentment obra de Pere Puiggarí i d'una colla de lletraferits amics seus (Xavier Cellés, Just Capdevila i Nicolas Birotteau). ${ }^{2}$ Es tracta del que Amadeu Pagès, marmessor de Tastú, va definir com «una societat d'epicuris». Que aquells poemes descordats, plens de malícia i de vida, que avui per a nosaltres són d'un gran interès lingüístic i sociològic, havien tingut una certa difusió, ho demostren els diversos exemplars manuscrits de què tenim notícia i que caldria tenir presents a l'hora de preparar-ne una possible edició crítica: a) un manuscrit conservat al CDACC de Perpinyà, actualment traslladat a la Mediateca d'aquella vila, a partir del qual vam preparar la nostra edició; b) el manuscrit amb què Josep Tastú havia preparat la seva, ara per ara perdut; c) el manuscrit titulat Les recreacions d'un bandit, pertanyent a una certa senyora L... («hereva d'una vella família de roba perpinyanesa»), que va servir perquè l'Almanac català del Rosselló de la revista Sant Joan i Barres en publiqués tres poemes en els números 4 («Lo lleó i l’ase»), 7 («Los cabdells») i 8 («La majordona collonada»); d) el que estava en poder del poeta Jordi Pere Cerdà, traspassat l'any 2011; e) el d'un escriptor rossellonès que ens va prometre que ens el deixaria veure, però que fins ara no ha tingut ocasió de poder-ho fer; f) i finalment un manuscrit que conté materials diversos dels segles XIX

\footnotetext{
1 Recollides també a la zona de Prats de Molló, Josep Massot i Muntaner va editar dues cançons eròtiques molt interessants: «Filla de Marxant» (núm. 32) i «Se n’ha gornit un tracte» (núm. 33) (Massot i Muntaner (ed.) 2006: 296297).

2 Jordi Pere Cerdà fins sembla suggerir que podrien ser pseudònims del mateix Puiggarí: «Tenim un poema d'ell [F. Jaubert de Paçà], un vers català, on es burla de Puiggarí, un capellà, director d'ensenyament religiós, historiador dels bisbes d'Elna, que fou la primera seu del país, també autor de llibres de gramàtica i d'ensenyament del castellà. Puiggarí ha quedat amb fama de llibertinatge groller. Les Recreacions d'un bandit que li són atribuïdes porten també diferents signatures; pot ser que siguin com una careta perquè tradueixen un estat de jocs de grup mal definit. Són aqueixos representants vilarets de la cultura rossellonesa que Merimée, segons sembla, posarà en burla en algunes línies de la novel la La venus d'Illa. No és l'erotisme de Puigagrí que mereix, sols, un juí despectiu, sinó la pobresa vulgar d'un llenguatge que es redueix, quasi sempre, a una baixesa absoluta. Els millors poetes, i els romàntics, han fet de l'erotisme un joc preciós; La Fontaine, una joieria de finesa. No té res de comú amb un Rector de Vallfogona i la part eròtica que se li ha atribuit; se sap que n'han afegit, com l'aigua que va a mar. Francesc Vicent Garcia és un mestre escriptor i poeta barroc de valor. Ja que tots dos són homes d'església, pot dir-se que són personatges escardalencs amb una budellada massa exhuberant» (Cerdà 2009: 63-64).
}

SCRIPTA, Revista internacional de literatura i cultura medieval i moderna, núm. 4 / desembre 2014 / pp. 80 - 95 ISSN: 2340-4841 · doi:10.7203/SCRIPTA.4.4487 
i xx, que figura en el fons de l'historiador cerdà Albert Salsas (1864-1940), ${ }^{3}$ dipositat a l'Arxiu Departamental de Perpinyà. ${ }^{4}$ De moment només hem pogut tenir accés als manuscrits a) i g).

Aquest darrer, el manuscrit del Fons Albert Salsas que duu el nom de Poesias Catalanas, ${ }^{5}$ incorpora després de l'última de les obres que ja vam editar («Lo santchristo de guix»), tres poemes anònims, dos escrits en català i un en occità, i encara dos més en francès, però aquests darrers d'autor conegut.

En el cas dels dos poemes en francès, per tant, no es tracta d'originals sinó d'una simple còpia d'obres ben conegudes. Són: a) «L'Éden», d'Edmond Haraucourt (1856-1941), que comença: «Dans l'Éther infini, plein de profonds mirages»; és un poema sobre els nostres primers pares procedent del llibre La Légende des sexes, poèmes histériques et profanes (1882), que com el títol indica vol ser una paròdia de La Légende des siècles de Victor Hugo; com que és un poema accessible i extens, en reproduïm només una primera estrofa en apèndix; i b) «Gaillardise» (publicat també amb el títol de «La Polissonnerie»), que comença: «Je cherche un petit bois touffu», poema molt celebrat de François-Marie Arouet, dit Voltaire (1694-1778), i que figura en totes les antologies de poesia eròtica francesa, però que per la seva brevetat copiem sencer.

Aquí editem, doncs, els tres poemes anònims escrits en català i occità, ben diferents de to i de contingut, i en el cas de «Tocar» copiat en una lletra clarament diferent, de manera que res no fa pensar que siguin d'un mateix autor. Per l'ordre en què els publiquem, el primer («Tocar») és un poema moralitzador i morigerat de contingut i d'expressió, que evita tota possible grolleria recorrent a metàfores i que predica que els plaers de la carn cal fruir-los amb moderació, de manera que en puguem fer ús durant més temps, consells que semblen donats des de l'experiència de la vida i per tant des d'una edat avançada. Ben al contrari, el segon («Sòmit d'un putaner») és un text desvergonyit i desenfrenat, un deliri eròtic que es complau en tota mena de transgressions, amb la clara voluntat d'escandalitzar (o de divertir...) essent repugnant i sacríleg, tot relativitzat per la coartada del somni. El tercer («La gavacha») és molt semblant a d'altres poemes del recull de Puiggarí («Lo waló», per exemple), en el sentit que consisteix en una anècdota explicada només amb la finalitat de preparar un acudit final, una sortida graciosa per inesperada, que aquí consisteix en la revelació sobtada de la completa innocència de la noia protagonista.

3 Salsas fou un historiador local, autor entre altres obres d'una Bibliographie de la Cerdagne (Perpinyà 1899) i de La Cerdagne espagnole (Perpinyà 1899); vegeu Delcor 1944: 163-167.

4 ADPO, Fons Albert Salsas, 7J 82-83. En aquest fons, sense inventariar i sense ordre ni concert, hi ha documents esparsos procedents de la seva col lecció privada, de totes les èpoques, molt interessants per a la història cultural i política del Rosselló i la Cerdanya.

5 Es tracta d'un manuscrit sense cobertes, escrit sobre paper ratllat, relligat en un quadern. Les mides són: 20,05 cm d'ample per 29,6 cm de llarg. També conté una lletra manuscrita, datada el 13 de juliol del 1937 i sense cap relació amb la resta, escrita per un tal Monsieur Casteil, que tracta de la còpia d'un manuscrit que tenia encomanada.

SCRIPTA, Revista internacional de literatura i cultura medieval i moderna, núm. 4 / desembre 2014 / pp. 80 - 95 ISSN: 2340-4841 · doi:10.7203/SCRIPTA.4.4487 
En el manuscrit es combinen aleatòriament les grafies catalanes tradicionals, quan a l'autor o al copista se'ls feien presents a la memòria, amb una transcripció de la pronunciació rossellonesa basada en les convencions gràfiques del francès, a les quals clarament ja estaven més avesats. Nosaltres, en comptes d'engavanyar el text original amb infinitat d'aclariments sobre la identitat i la pronunciació de gairebé cada paraula, editem i anotem tots tres poemes en grafia moderna però respectant-ne les particularitats fonètiques reflectides en el manuscrit. És amb aquesta intenció que, com ja hem fet en altres publicacions, adoptem la grafia ô, que permet representar una $o$ tancada rossellonesa indicant al mateix temps que cal pronunciar-la [u], i sense deformar substancialment la imatge gràfica habitual del mot a què pertany, de la qual depèn la comprensió immediata del sentit: escrivim gelôsa/usa en comptes de gelosa/usa, que no informa que es tracta d'una rima, o gelusa/ usa, on costa de reconèixer quina és la primera paraula. A més, hi afegim la transcripció literal dels originals perquè el lector interessat hi pugui aclarir qualsevol dubte o reserva, i en el cas del poema en occità, també una traducció.

\section{a) Tocar}

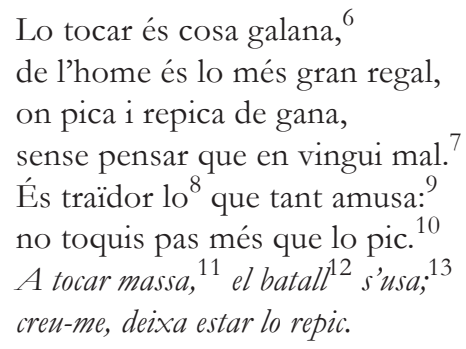

6 galana: «notable, que excel leix, en bon sentit o en mal sentib» (GDLC; galan «bell i graciós, que captiva per les seves gràcies o encants», DCVB).

7 que en vingui mal: 'que en pugui venir cap mal' (venir 'esdevenir'; ross., CBDN, VDR).

8 lo: 'allò'.

9 amusa: 'diverteix' (occitanisme que DCVB documenta en Ramon Llull; oc. amusar, fr. amuser).

10 que lo pic: 'que un sol pic, que una sola vegada'.

11 a tocar massa: 'de massa tocar, per massa tocar' (fr.; cf. À trop manger sa mère on devient orphelin).

12 massa, el batall: encara que al manuscrit hi hagi masse lo batail, considerem que lo darrere vocal representa "l (de la mateia manera que $l o$ davant de vocal representa $l$ ), com queda demostrat tant per la mètrica com per la grafia al en les successives aparicions de la tornada. Òbviament, batall és una metàfora tradicional per 'penis' i tocar (el batall) és 'copular'.

13 s'usa: 'es desgasta, es deteriora progressivament per l'ús' (oc. s'usar, fr. s'user, però no és a CBDN ni a VDR). 
Vés a pler, ${ }^{14}$ si vos ${ }^{15}$ durar força, no toquis pas de massa foc, ${ }^{16}$ sinó te faltarà la força: ${ }^{17}$

lo que és pas fort dura poc.

És boig qui de $\operatorname{sos}^{18}$ plers abusa;

si flaques, ${ }^{19}$ ja seràs bonic... ${ }^{20}$

No toquis pas més que lo pic. ${ }^{21}$

A tocar massa, el batall s'usa;

creu-me, deixa estar lo repic.

Si no moderes pas ta fúria, ${ }^{22}$

per aqueix joc tan agradant, ${ }^{23}$

de $[\text { cert }]^{24}$ crenyim $^{25}$ que res no suri: ${ }^{26}$

cul i mollets ${ }^{27}$ hi passaran. ${ }^{28}$

14 a pler: 'a pleret (a poc a poc, sense pressa)', amb moderació.

15 vos: 'vols'.

16 de massa foc: 'amb massa passió'.

17 la força: en el manuscrit las forces (va ratllar la $s$ en adonar-se que li fallava la rima).

18 de sos: 'dels seus'; en el manuscrit, das sus.

19 flaques: 'defalleixes, flaqueges' (flacar, DCVB, CBDN, VDR).

20 ... bonic: no hem trobat enregistrada l'expressió irònica ja seràs bonic, però el seu sentit és prou transparent en el context: 'per bonic que siguis, estaràs ben llest'.

21 Des del punt de vista de l'estructura de l'estrofa, aquest vers hi sobra.

22 fúria: 'ímpetu'. Malgrat la grafia del manuscrit, resulta evident que la pronunciació prevista era furi, ja que rima amb suri.

23 agradant: 'agradós'.

24 Una taca de tinta impedeix de llegir un mot monosil làbic, que transcrivim segons el significat que hipotèticament li atribuïm.

25 crenyim: 'temem' (crényer, de l'oc. crénher).

26 suri: 'prosperi, s'enforteixi' («fer que alguna cosa es mantingui viva i en creixença, que prosperi, que augmenti en vitalitat o en força», $D C V B)$.

27 mollets: 'ventres de la cama' (fr. mollet), sinècdoque per cames.

28 hi passaran: 's'hi malmetran, es deterioraran, s'espatllaran, deixaran de servir o de ser eficaços' (ho relacionem

SCRIPTA, Revista internacional de literatura i cultura medieval i moderna, núm. 4 / desembre 2014 / pp. 80 - 95 


\author{
Sec i prim com una filôsa, ${ }^{29}$ \\ per força ja faràs a pic. ${ }^{30}$ \\ A tocar massa, el batall s'usa; \\ creu-me, deixa estar lo repic. \\ I ta muller, que hauràs gustada \\ la repicant ${ }^{31}$ primer $^{32}$ de foc, ${ }^{33}$ \\ ¿què farà, se vent ${ }^{34}$ privada, \\ quan no li donaràs que un toc? ${ }^{35}$ \\ Ah!, cren ${ }^{36}$ que la dona gelôsa ${ }^{37}$ \\ no pringui ${ }^{38}$ ajuda d'un amic! \\ A tocar massa, el batall s'usa; \\ creu-me, deixa estar lo repic.
}

hipotèticament amb passar-se «alterar-se en mal; perdre la frescor, el bon estat natural» (DCVB), amb l'expressió passar avall 'morir-se; perdre's, desaparèixer per sempre' (Rodamots) i sobretot amb el francès y passer 'morir-se, deixar-hi la pell').

29 filôsa: com ja hem dit, amb la grafia ô volem indicar alhora que es tracta d'una $o$ tancada i que el manuscrit indica que cal pronunciar-la [u] (en aquest cas, filôsa ha de rimar amb usa). De fet, la grafia del manuscrit, fillouse, correspondria més aviat a fillôsa [fi'Kuzə] o [fi'juzə], pronunciacions que no creiem possibles.

30 faràs a pic: 'aniràs a pic' (no hem trobat enregistrat en català fer a pic, en fr. hi ha couler à pic 'anar a pic' i tomber à pic 'caure a plom', però no pas faire à pic).

31 la repicant: 'repicant-la' (aquí, eufemísticament, 'tenint-hi coit dues o més vegades seguides').

32 primer: 'abans d'ara (en un temps anterior, quan eres més jove)'.

33 de foc: 'fogosament, apassionadament, amb vehemència, amb insistència'.

34 se vent: 'veient-se, quan es vegi' (se ve(e)nt).

35 quan no li donaràs que un toc: 'quan només li podràs donar un sol toc' (fr.).

36 cren: per creny 'tem (tu)' (verb crényer, ross.; de l'oc. crénher 'témer').

37 gelôsa: cal pronunciar [3ə’luzə].

38 pringui: 'prengui' (ross., VDR).

SCRIPTA, Revista internacional de literatura i cultura medieval i moderna, núm. 4 / desembre 2014 / pp. 80 - 95 


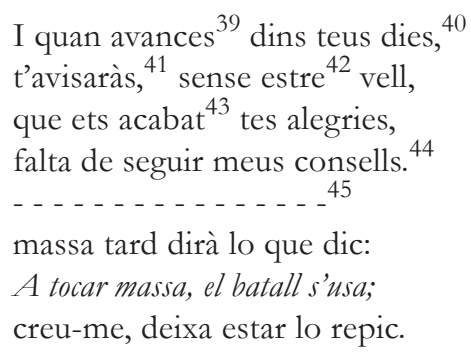

\section{Transcripció literal del text del manuscrit:}

Tocar | Lo toca es cosa galane | de l'home es lo mès gran ragal | on pique y rapique degane | sense pensar qu'en vingui mal!! | Es trahido lo qua tant amouse | no toquis pas mès que lo pic | a tocar masse lo bataill s'ouse | creu mè, dèche estar lo rapic ||

Bés a ple si vos dura force $\mid$ no toquis pas de masse foc $\mid$ sino ta faltera las forces ${ }^{46} \mid$ lo quès pas -fort dura poc | Es botj qui das sus plès abuse | si flacas jà saras bonich | no toquis pas mès qua lo pic | a tocar masse lo batail s'ouse | Creu mè, deche estar lo rapic | |

Si no moderas pas ta furia $\mid$ Par aqueix joc tan agradan, $\mid \mathrm{Da}-{ }^{47}$ cragnim qu'a res no suri $\mid$ Cou'l y mollets y passaran. | Sec y prim coum oune fillouse | Par force ja faras a pic | a tocar massa al bataill s'ouse | creou me, dèche estar lou rapic. ||

Y ta muller qu'auras goustada | La rapican primé da foc | qua fera? sa ben pribada | qouan no l'y douneras [corregim doumeras] qu'un toc. | ah crain qu'a la done jalouse | no pringui ajuda d'un amic | a tocar-massa al bataill souse | creou mè, deche estar lou rapic ||

39 avances: en el manuscrit, abancais (abans havíem trobat el subjuntiu toquis, amb -i).

40 ...dies: 'a mesura que vagis fent anys'.

41 t'avisaràs: 't'adonaràs' (ross.; oc. s'avisar, fr. s'aviser).

42 estre: 'ser' (ross.; oc. estre).

43 ets acabat: 'has acabat' («un gran nombre de verbs es conjuga amb l'auxiliar ser, o més aviat amb una barreja de ser i d'haver: sun menjat, ets menjat, ha menjat, sem menjat, seu menjat, han menjath, VDR, p. 23). Corregim est, que suposem un lapsus motivat per la influència del francès, per ets.

44 falta de: 'per culpa de' (fr. faute de 'per manca de').

45 L'estrofa i la falta de rima revelen que en el manuscrit hi falta un vers.

46 las forces: primer havia escrit las forces i després va ratllar la $s$ final perquè li espatllava la rima.

47 Una taca de tinta impedeix llegir el mot (d’una sola síl laba) que hi ha a sota.

SCRIPTA, Revista internacional de literatura i cultura medieval i moderna, núm. 4 / desembre 2014 / pp. 80 - 95 
Enric Prat \& Pep Vila. Tres poemes eròtics en català i occità copiats en un cançoner rossellonès

y qouan abancais dins teous dies | tabiseras sense estre bieil | qu'est acabat t'as alagrias | falta de saguir meus counseils | massa tart dira lo qu'a dic | a tocar masse al bataill s'ouse | Creou mè deche estar lou rapic ||

\title{
b) Sòmit ${ }^{48}$ d'un putaner $^{\prime}$
}

\author{
Mes mirau quina desditja ${ }^{49}$ \\ me va subceir ${ }^{50}$ l'altra nit! \\ Eri $^{51}$ foll de la privitja ${ }^{52}$ \\ que tenia al cap del vit. \\ Sabereu ${ }^{53}$ que somiava \\ que enculavi ${ }^{54}$ dôs reddôrs, ${ }^{55}$ \\ $i$ que el fotral ${ }^{56}$ de mon avi \\ me gratava los collôns. ${ }^{57}$ \\ Lo vit tot untat de merda \\ me xucava ${ }^{58}$ la muller; \\ jo li llepavi l'esquerda \\ i el còrrec caganer.
}

48 sòmit: 'somni' (ross.; però: «['sэmit] (forma usada en el llenguatge parlat de tots els dialectes)», DCVB,).

49 desditja: 'dissort' (cast. desdicha, amb sonorització rossellonesa).

50 subceir: 'succeir' (reflecteix la pronunciació [supsə’i] o [sutsə’i], en comptes de [suksə’i]).

51 eri: 'jo era'; aquí, 'estava'.

52 privitja: 'pruïja, coïssor' (ross., $C B D N, V D R)$.

53 sabereu: 'sabreu'.

54 enculavi: '(jo) enculava'.

55 reddôrs: 'rectors' (el grup $c t$ es pronuncia $d d$, amb sonorització i assimilació característiques del rossellonès: rectôrs > reddôrs [rəd'dús]).

56 fotral: 'imbècil, bèstia, ximple, beneit' (CBDN, VDR; oc. fotral).

57 collôns: pronunciat cullús [ku'Kus] en rossellonès (com reflecteix la grafia del manuscrit: coullous).

58 xucava: 'xuclava' (CBDN, VDR; oc. chucar).

SCRIPTA, Revista internacional de literatura i cultura medieval i moderna, núm. 4 / desembre 2014 / pp. 80 - 95 ISSN: 2340-4841 $\cdot$ doi:10.7203/SCRIPTA.4.4487 
Los ${ }^{59}$ collôns botats ${ }^{60}$ com toronges, ${ }^{61}$

a fe de Déu, eri ${ }^{62}$ calent;

'gés ${ }^{63}$ cardat totes les monges,

quan ${ }^{64}$ n'hi hagés hagudes cent.

La gôssa de la portera

no feia que ${ }^{65}$ gemegar;

l'hi vai fotre per l'ullera ${ }^{66}$

i después va cadellar.

Sants i santes s'enculaven,

criatures, animals.

Les macarelles ${ }^{67}$ cridaven:

«Anem allà, ${ }^{68}$ fotrals!».

Si, pel llamp!, 70 'gés vist ma mare,

encara que fôs son fill,

m'hi 'gés fet al para-para ${ }^{71}$

per li eixamplar el conill. ${ }^{72}$

59 los: se sobreentén 'amb els' (fr.).

60 botats: 'inflats' (botar 'botir, inflar', CBDN, VDR).

61 toronges: 'taronges' (ross. toronge o toronjo, masc., CBDN, VDR)

62 eri: 'jo era' ('estava').

63 'gés: 'hagués' (afèresi d’hagés 'hagués’),

64 quan: 'fins i tot quan, encara que'.

65 no feia que: 'no feia més que' (fr.).

66 ullera: 'anus'. Corregim ovère, que ens sembla un error de còpia causat per la confusió entre $u$ i $l l$ o bé perquè el copista no va entendre el sentit del mot i el va esmenar.

67 macarelles: 'alcavotes' (macarell 'macarró, arlot', CBDN, VDR; oc. macarè̀).

68 anem allà!: equival aquí al fr. allons-y! ‘endavant!’.

69 Un altre vers coix, amb només sis síl labes.

70 pel llamp!: exclamació que expressa resolució, determinació.

71 m'bi 'gés fet al para-para: 'm'hauria posat a fer amb ella el para-para, m'hi hauria dedicat al para-para'. A més del sentit obvi que se li dóna en aquest context, suposem que para-para és la denominació d'un joc en què cal copsar alguna cosa (parar «estendre o presentar una part del cos, un recipient, en posició o manera apta per a rebre allò que ens donen, tiren, apliquen, etc.», DCVB; la repetició recorda altres noms de jocs, com ara el fr. cache-cache o el cast. pillapilla).

72 conill: 'vulva' (ross., CBDN, VDR).

SCRIPTA, Revista internacional de literatura i cultura medieval i moderna, núm. 4 / desembre 2014 / pp. 80 - 95 


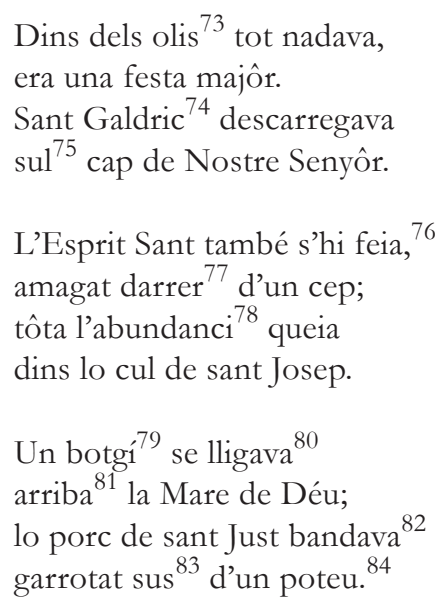

73 olis: aquí, usat en el sentit de 'sucs, fluids lubricants'.

74 sant Galdric: sant Galderic és el patró tradicional de la pagesia catalana.

75 sul: 'sobre el', contracció rossellonesa.

76 s'hi feia: 's'hi dedicava amb entusiasme' (cf. «fer-s'bi (en una cosa): esforçar-s’hi, lluitar», DCVB).

77 darrer: en el manuscrit hi ha darrera, però la mètrica ens fa veure que cal pronunciar-ho darrer («darré Apòcope de darrere "M'amagui darré d'un rideu" (Saisset)», VDR).

78 abundanci: pronunciació rossellonesa d'abundància.

79 botgi: 'botxí' ('home malvat, cruel, que fa sofrir'; pronunciat amb sonorització rossellonesa).

80 se lligava: no sabem quin és el sentit que es vol donar aquí a aquest mot, però en el context del poema ens suggereix la còpula (lligar: «unir dues o més coses de manera que hi hagi entre elles un encadenament, no hi hagi interrupció, que formin un tot homogeni», $D C V B$ ). D’altra banda, com que és un vers hipomètric, podria ser que hi faltés un mot monosil làbic.

81 arriba: a falta d'una hipòtesi millor, i en un context tan volgudament sacríleg, ¿podria ser que es tractés d'un castellanisme (arriba 'sobre, damunt') que no consta enlloc que hagi estat mai usat en català?

82 bandava: 'trempava, tenia una erecció' (fr. bander 'tibar', familiarment 'trempar'; no és a CBDN ni a VDR).

83 sus: 'sobre' (ross.).

84 poteu: 'pal' (oc. postèl, fr. poteau; CBDN, VDR).

SCRIPTA, Revista internacional de literatura i cultura medieval i moderna, núm. 4 / desembre 2014 / pp. 80 - 95 
Culs, conills, ${ }^{85}$ bônys ${ }^{86}$ i tetes, pel meu vit tot va passar; me vai ${ }^{87}$ fer més de cent punyetes ...i me vari ${ }^{88}$ despertar.

\section{Transcripció literal del text del manuscrit:}

\section{Somit d'un Putané}

Mes mirau qu'ine dasditje | me va subsehir l'altre nit ? | Eri foll de la pribitge | que tenia al cap del bit. | |

Sabareu que soumiabe | qu'encoulabi dous raddous, | y qu'a l' foutral de moun abi | me grattaba los cullous. ||

Lou bit tot ountat de merde | me choucaba la moller | Jo l'y llapabi l'asquerde | y l' correq caganer. |

Lous coullous botats com toronges | a fé de Deou, eri calent, | Jes cardat totas las monges | quan n’y agés agudas cent. ||

La gousse de la portère | no feya qu'a jamegar | li bay fotre per l'ouère | y despues ba cadeillar. || Sants y santes s'encoulaben | criatoures, animals | Las maquareillas cridaban | anem, alla, foutrals. ||

Si pel llam j'es bist ma mare | Encara que fus son fill, | Mi j'es fait al pare pare |

Per li axamplar l' conill. ||

Dins dels olis tot nadaba, | ere una festa majou, | san Galdrig d'escarragaba |

sou'l cap de nostra Senyou. ||

L’esprit san també si feya | amagat darrera d'un cep | Toute l'abundanci queya |

Dins lou coul de san Jousep. ||

85 conills: 'vulves' (ross.).

86 bônys: suposem que bony fa referència al mont de Venus -a la «Carta d'en Jordi Capdeville al fra Pere» (Poesia eroticoburlesca..., p. 102) hi trobem: «cunys y culs, motas y tetas», on mota es refereix a la mata de pèl pubià.

87 vai: 'vaig'.

88 vari: 'vaig' («vari: vaig, en el pretèrit perfet perifràstic», VDR; en el vers anterior, en canvi: me vai fer).

SCRIPTA, Revista internacional de literatura i cultura medieval i moderna, núm. 4 / desembre 2014 / pp. 80 - 95 
Oun Boutgi sa lligaba | Arriba la mare de Deou; | Lou porc de San Joust bandabe | garroutat sous d'oun pouteou. ||

Couls, counills, bounys i tetas, | Pel meou bit tot ba passa | Me bay fé mes de cent puñetas | y me bari desparta.

\title{
c) La gavacha ${ }^{89}$
}

\author{
Una polida vendemiaire, \\ arribant un jorn ${ }^{90}$ a Perpinhan, ${ }^{91}$ \\ se fasquèt lèu un carinhaire ${ }^{92}$ \\ que me la saupèt bitonar. ${ }^{93}$
}

89 gavacha: en el manuscrit, gabatge, que és la pronunciació (o la interpretació) rossellonesa de l'occità gavacha, amb sonorització (gavacha [ga' $\square$ at $\mathrm{o}]>$ gavatja [gə’ $\square$ adzə]). Respecte a la a final en occità (que hem transcrit per [o] seguint DCOOC, p. XIII, però que segons els parlars, pot ser pronunciada, o si més no ha estat transcrita, com [o], [o $],[\mathrm{o}],[\mathrm{a}]$, [a], [ə] i [œ]), observem que el manuscrit l'escriu inconsistentment de tres maneres diferents: a) una, poulida, bitouna; b) ère, motte, paurotte, tuste; i c) paurouno, encaro, sabio; que això no correspon a cap diferència fonètica ho demostra el fet que paurouno [paw'runo] hi rima amb bitouna [bi'tuno]... A més, cal tenir en compte que mentre que en català rossellonès gavatx és un «terme pejoratiu per a designar els que no parlen català i que són occitans» (CBDN), l'occità gavach és un «terme despectiu que s'aplica [...] a un pagès, a un muntanyès» (VDR) («montagnard; étranger; rustre, grossier», $L D O F)$. Tenint en compte que el poema passa a Perpinyà i està escrit en occità, és probable que a la nostra gavatxa se li vulguin aplicar tots dos significats: és llenguadociana i, a més d’innocent i bonica, és rústega i ignorant.

90 jorn: com reflecteix la grafia de l'original (joun), es pronuncia [dzun] (també [dzur]).

91 Perpinhan: pronunciat Perpinyà ([perpi’na], rima amb bitonar [bitu’na]).

92 carinhaire: 'festejador', variant de l'oc. calinhaire («galant, amoureux», LDOF), per contaminació amb castellanismes del català com carit (del cast. querido) o carinyós. No enregistrat (CBDN, VDR).

93 bitonar: 'copular'. El verb bitonar (en aquest mateix poema usat tant intransitivament com, des del punt de vista de l'home, transitivament) no l'hem trobat enregistrat ni en català o occità (TLF, ADOF, LDOF) ni en francès (*bitonner, *bitounner...; GRLF, RDHLF, DFNC), però sí el verb anàleg biter: «(1884) dérivé de bite sur le modèle pine/piner, est un mot vulgaire pour 'posséder charnellement', RDHLF». El sentit eròtic dels mots fr. bite (o bitte) i oc. bita 'penis' sembla una metàfora evident basada en el sentit mariner d'aquests mateixos mots ( $c f$. bita «cilindre de ferro o d'acer que, subjecte a la coberta d'un vaixell, serveix per a amarrar-hi una cadena o un cable», GDLC), però els diccionaris francesos informen que això és històricament impossible perquè «le pillier de fonte, d'allure phallique, est bien plus tardif» (RDHLF); podria ser, doncs, que derivés d'una arrel germànica que encara manté el significat de 'biga' en algunes llengües escandinaves, entre d'altres hipòtesis. Als diccionaris rossellonesos (CBDN, VDR) no hi consta bita 


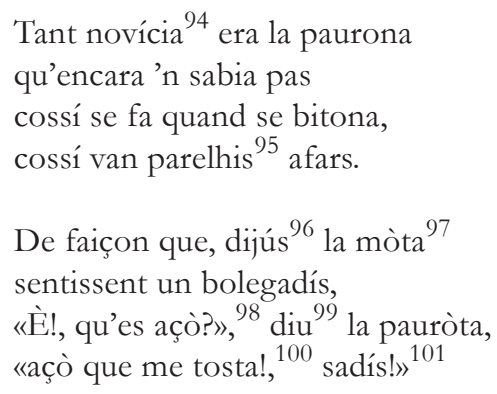

\section{Traducció:}

Una bonica veremadora, arribant un dia a Perpinyà, va trobar (es va fer) aviat un festejador, que me la va saber bitonar. || Tan novella era la pobreta que encara no sabia com es fa quan es bitona, com van aquestes coses. || De manera que, sentint-se un bellugueig sota la mota [la mata de pèl púbic], «Eh!, què és això?», diu la pobrota, «això que em tusta!, Déu sant!».

\section{Transcripció literal del text del manuscrit:}

\section{La Gabatge}

Una poulida vendemiaire | arriban oun joun a Perpiñia | se fasquet leu un carignaïre | que me la saupet bitouna. ||

'penis', però tenim testimonis del seu ús en català: «vehent traure la bita | del conaco maternal» (Prat / Vila 2000: 125) i els noms satírics d'eclesiàstics «fra Biteri» (Prat / Vila 2000: 134) i «mossèn Bitarol» (Burlaner 1995).

94 novicia: pronunciat novici en occità.

95 parelhis: per parelhs, però a l'original diu pareillis.

96 dijus: variant de dejús 'sota'.

97 mòta: 'pèl púbic' («clap de pèls, de filaments, etc., a la superfície d'un òrgan o d’una part del cos», DIEC2; en fr. motte 'gleva, terròs' i ‘motte de gazon' -a més de 'gespa', gazon també pot ser, metafòricament, 'poils du pénil').

98 açò: catalanisme per aquò [a'ko].

99 diu: català per ditř 'diu'.

100 tosta: 'tusta'; és a dir, creiem que és el català tustar ('colpejar', 'trucar a la porta demanant entrar') i no pas un hipotètic oc. *tustar [tys'ta] o l'oc. tostar 'torrar, rostir'.

101 sadís!: possiblement, exclamació eufemística per sant Di(e)u! (com en el cas del castellà ipardiez!, deformació de ipor Dios:). 
Tant novici ère la paurouno | qu'encaro n' sabio pas | coussi se fa quand sé bitouna | coussi van pareillis affas. ||

De faiçou que dijus la motte, | sentissent un boulegadis, | Eh qués aço, diu la paurotte | aço que me tuste, sadis?

\section{Apèndix: Els poemes en francès}

\section{I. «L'Éden» d'Edmond Haraucourt}

El primer dels dos poemes en francès copiats en aquest recull és L'Éden, del poeta, novel lista, periodista $\mathrm{i}$ compositor francés Edmond Haraucourt (1856-1941) ${ }^{102}$ fou inspirat per «Le Sacre de la femme» de Victor Hugo (a La Légende des siècles). Formava part dell libre que Haraucourt havia publicat l'any $1882 \mathrm{amb}$ el pseudònim Sire de Chambley, titulat La Légende des sexes, poèmes hystériques et profanes, paròdia, com es veu, del volum de Victor Hugo. Aquesta n'és l'estrofa inicial, on Adam es desperta d'una nit febrosa i descobreix per primera vegada Eva al seu costat:

Dans l'éther infini, plein de profonds mirages,

Dans l'azur insondable et vierge de nuages,

Le grand soleil montait lentement, gravement:

Et l'Éden, ébloui du long rayonnement,

S'éveilla. La nature amoureuse et ravie

Entonna le concert éclatant de la vie.

Tout remuait: Adam, le seul et le dernier,

Dormait les poings fermés, à l'ombre d'un pommier.

De larges ronflements bourdonnaient sur sa lèvre:

Il avait eu, la nuit, des douleurs et des fièvres;

Il avait fait un rêve, il avait mal aux reins:

Il avait cru voir Dieu, du haut des cieux sereins,

Descendre à petits pas, et la dextre divine

Avait pendant longtemps fouillé dans sa poitrine

Pour y ravir un os qu'elle aviat emporté...

Adam dormait toujours. Debout à son côté,

Ève le regardait, soucieuse, étonnée.

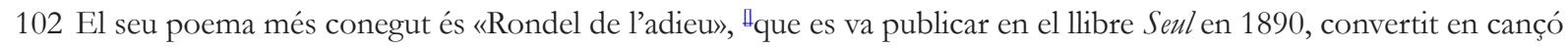
per Francesco Paolo Tosti l'any 1902: «Partir, c'est mourir un peu, | C'est mourir à ce qu’on aime; | On laisse un peu de soi-même en toute heure et dans tout lieu...» 
Enric Prat \& Pep Vila. Tres poemes eròtics en català i occità copiats en un cançoner rossellonès

II. «La Gaillardise» o «La Polissonnerie» (1729) de Voltaire

- Je cherche un petit bois touffu,

Que vous portez, Aminthe,

Qui couvre, s'il n'est pas tondu,

Un gentil labyrinthe.

Tous les mois, on voit quelques fleurs

Colorer le rivage;

Laissez-moi verser quelques pleurs

Dans ce joli bocage.

- Allez, monsieur, porter vos pleurs

Sur un autre rivage;

Vous pourriez bien gâter les fleurs

De mon joli bocage;

Car, si vous pleuriez tout de bon,

Des pleurs comme les vôtres

Pourraient, dans une autre saison,

M'en faire verser d'autres.

- Quoil vous craignez l'évènement

De l'amoureux mystère;

Vous ne savez donc pas comment

On agit à Cythère;

L’amant, modérant sa raison,

Dans cette aimable guerre,

Sait bien arroser la gazon

Sans imbiber la terre.

- Je voudrais bien, mon cher amant,

Hasarder pour vous plaire;

Mais dans ce fortuné moment

On ne se connait guère.

L'amour maitrisant vos désirs,

Vous ne seriez plus maître

De retrancher de nos plaisirs

Ce qui vous donna l'être.

SCRIPTA, Revista internacional de literatura i cultura medieval i moderna, núm. 4 / desembre 2014 / pp. 80 - 95 
Enric Prat \& Pep Vila. Tres poemes eròtics en català i occità copiats en un cançoner rossellonès

\section{Bibliografia.}

ADOF Alibèrt, Loís (1935) Dictionnaire occitan-français d'après les parlers languedociens, Tolosa, Institut d'Estudis Occitans (reed. 1978).

CBDN Camps, Christian / Botet, Renat (2013) Diccionari nord català. Dictionnaire nord catalan, Canet de Rosselló, Trabucaire.

Cerdà, Jordi Pere (2009) Finestrals d'un capvespre, Canet de Rosselló, Trabucaire.

DCOOC Balaguer, Claudi / Pojada, Patrici (2005) Diccionari català-occità, occità-català, Barcelona, Llibres de l'Índex, 2005.

DCVB Alcover, Antoni M. / Moll, Francesc de B. (1926-1962) Diccionari català-valencià-balear, Palma de Mallorca, Editorial Moll.

Delcor, Mathias (1944) «Albert Salsas (1864-1940), sa vie, son œuvre», Bulletin de la Société agricole scientifique et littéraire des Pyrénées-Orientales, 62, pp. 163-167.

DFNC Cellard, Jacques / Rey, Alain (1991) Dictionnaire du français non conventionnel, Hachette, París (2a ed.).

DIEC2 Diccionari de la llengua catalana, Barcelona, Institut d'Estudis Catalans, 2007 (2a edició).

GDLC Gran diccionari de la llengua catalana, Barcelona, Enciclopèdia Catalana, 1998 (Consultat per Internet).

GRLF Le Grand Robert de la langue française, París, 2001 (2 ed.).

LDOF Laux, Christian (2001) Dictionnaire occitan-français. Languedocien, Reialmont, Section du Tarn de l'Institut d'Études Occitanes.

LTF Mistral, Frédéric (1878-1886) Lon Tresor dón Felibrige

Massot i Muntaner, Josep (ed.) (2006) Obra del Cançoner Popular de Catalunya. Materials, vol. XVI (Memòries de Missions de Recerca, per Joan Amades i Palmira Jaquetti), Barcelona, Publicacions de l'Abadia de Montserrat («Missió a Prats de Molló (1934)», pp. 296-297).

Pere Burlaner (1995) Els contes de mossèn Bitarol, edició de Jaume Queralt, Barcelona, Llibres de l'Índex.

Prat, Enric / Vila, Pep (2000) Poesia eroticoburlesca rossellonesa del s. XIX, Canet de Rosselló, Trabucaire. RDHLF Le Robert. Dictionnaire historique de la langue française, París, 1992 (2a ed., 1998).

VDR Verdaguer, Pere (2002) Diccionari del rossellonès, Barcelona, Edicions 62.

SCRIPTA, Revista internacional de literatura i cultura medieval i moderna, núm. 4 / desembre 2014 / pp. 80 - 95 